\title{
VALUES AS PREDICTORS OF ENVIRONMENTAL ATTITUDES: EVIDENCE FOR CONSISTENCY ACROSS 14 COUNTRIES
}

\author{
P. Wesley SChUltZ AND LyNNETte ZeleZny \\ Department of Psychology, California State University, San Marlos, CA, U.S.A. and California State University, \\ Fresno, CA, U.S.A.
}

\begin{abstract}
A multinational study is reported on the relationship between values and attitudes. Environmental attitudes were measured using the revised New Environmental Paradigm (NEP: Dunlap et al., 1992) and Thompson and Barton's (1994) ecocentrism-anthropocentrism scales. Other measures included gender, SES, religion, and Schwartz's (1994) universal values scale. Survey data were obtained from college students in 14 countries. A sample of 2160 participants was obtained through university contacts in each country. Results found support for the distinction between different types of environmental attitudes. Regression analyses revealed a consistent pattern of findings across countries. Scores on the NEP scale and the ecocentrism scale were predicted by universalism (positively), power (negatively), and tradition (negatively). In contrast, anthropocentric concerns were significantly related to benevolence (negatively), power (positively), tradition (positively), and security (positively). Overall, these findings support the value-basis theory of environmental attitudes.
\end{abstract}

\section{Introduction}

Since the beginning of the environmental movement over 30 years ago, social psychologists have attempted to understand the forces that lead people to be concerned about environmental issues. This research has been guided largely by traditional attitude theory, as well as by social psychological theories of prosocial behavior. However, for a variety of reasons, this re- search stagnated in the mid-1980s (Darley \& Gilbert, 1985). Within the past five years, a new approach to the study of environmental issues has opened promising lines of research and has begun to ask fundamentally different questions. Rather than investigating general attitudes about environmental issues, recent research has attempted to identify underlying values that pro- vide a basis for environmental attitudes. Thus, two people could be equally concerned about environmental issues, but for fundamentally different reasons. This paper presents the results from a multinational study of the relationship between values and environ- mental attitudes.

Studies of attitudes toward environmental issues have begun to move away from an examination of general environmental concern and toward a more differentiated conceptualization of environmental attitude formations. Stern and Dietz (1994) proposed a value- basis theory for environmental concern which states that environmental attitudes are the result of a person's more general set of values. Specifically, they pro- posed that there are three distinct bases for environmental attitudes: the individual, all people, and all living things. Egoistic environmental attitudes are based on beliefs about the effect that environmental destruction may have on the individual. Thus, the environment should be protected because I don't want to breath polluted air, or I don't want to drink dirty water. Social-altruistic environmental attitudes are based on human benefits or human goals. Protecting the environment is important be- cause of the long-term consequences it may have on other people. Finally, biocentric attitudes center on the inherent value of the natural environment. Humans should not harm nature because we are a part of nature; species have a right to continue; nature has intrinsic rights broader than mere species survival (Kempton et al., 1994). A similar tripartite classification has been proposed by Merchant (1992) who termed the dimensions egocentric, anthropocentric, and ecocentric respectively. We use the terms socialaltruistic and anthropocentric interchangeably, as we do biocentric and ecocentric.

Values are conceptualized as important life goals or standards which serve as guiding principles in a person's life (Rokeach, 1973). Values are distinct from attitudes or beliefs because they function as an organized system and are typically viewed as determinants of attitudes and behaviors (Olson \& Zanna, 1994). Expanding on Rokeach's (1973) seminal work on the structure of values, Schwartz 
$(1992,1994)$ has developed an instrument to measure dimensions of values which are considered to be universal across all people. The instrument is composed of 52 value- items that represent ten value types. Respondents are asked to rate the importance of each value-item on a Likert scale. Large-scale cross-cultural surveys by Schwartz (1994) have demonstrated that the ten value types can be collapsed into four value categories: openness to change, conservatism, self-transcendence, and self-enhancement. Openness to change includes self-direction, stimulation, and hendonism and is measured with value items like creativity, curiosity, daringness, and variety in life. Conservatism (we will henceforth use the label of tradition for this dimension, as suggested by Stern et al., 1995) includes conformity, traditionalism, and security. Self-transcendence includes universalism and benevolence, while self-enhancement includes power and achievement. The breakdown of Schwartz's value-items is presented in Table 1.

Stern and Dietz's (1994) value-basis theory provides a new direction for social psychological research on environmental attitudes. However, such research should be linked with research findings from the last 20 years, during which time the most prominent mea- sure of environmental attitudes was the New Environ- mental Paradigm (NEP). Dunlap and Van Liere (1978) and Dunlap et al. (1992) have argued that a new view of the relationship between humans and thenatural environment is beginning to develop in Western nations. Within the existing dominant social paradigm, humans are viewed as separate from nature, while the emerging NEP views humans as an integral part of nature. Stern and Dietz (1994) suggested that the NEP is conceptually similar to their notion of bio- centrism, although no evidence has been provided to support this hypothesis.

\section{Research on values and environmental attitudes}

Research on the emergence of biocentrically-based environmental attitudes in the U.S. has found mixed results. Dunlap et al. (1992) reported a comparison of scores on eight items from their NEP scale taken in 1976 and again in 1990. Atboth times, a representative sample of Washington state residents completed a survey containing the same NEP items. The results showed that in 1976,71\% of the respondents endorsed all eight of the items, and by 1990 endorsement had increased to $78 \%$. Dunlap et al. (1992) considered this to be evidence for an emerging reconceptualization of the relationship between humans and nature. 


\begin{tabular}{|c|c|c|c|}
\hline \multicolumn{4}{|c|}{$\begin{array}{c}\text { TABLE } 1 \\
\text { Value-items from Schwart'z values instrument }\end{array}$} \\
\hline Self-transcendence & Self-enhancement & Openness & Tradition \\
\hline Universalism & Power & Self-direction & Tradition \\
\hline $\begin{array}{l}\text { Protecting the } \\
\text { environment* }\end{array}$ & Social power* & Creativity* & Devout* \\
\hline A world of beauty* & Authority* & Curious* & Respect for tradition* \\
\hline Unity with nature* & Wealth* & Freedom* & Humble* \\
\hline Broad-minded* & $\begin{array}{l}\text { Preserving my public } \\
\text { image* }\end{array}$ & $\begin{array}{l}\text { Choosing own } \\
\text { goals* }\end{array}$ & Moderate* \\
\hline Social justice & Social recognition & Independent & Accepting portion in life \\
\hline Wisdom & & & Detachment \\
\hline Equality & Achievement & Stimulation & \\
\hline A world at peace & Successful* & Daring* & Conformity \\
\hline \multirow[t]{2}{*}{ Inner harmony } & Capable* & A varied life* & Politeness* \\
\hline & Ambitious* & An exciting life* & $\begin{array}{l}\text { Honoring parents and } \\
\text { elders* }\end{array}$ \\
\hline Benevolence & Influential* & & Obedient* \\
\hline Helpful* & Intelligent & Hedonism & Self-discipline* \\
\hline Honest* & Self-respect & Pleasure* & \\
\hline Forgiving* & & Enjoying life* & Security \\
\hline Loyal* & & & Clean* \\
\hline Responsible & & & National security* \\
\hline True-friendship & & & Social order* \\
\hline A spiritual life & & & Family security* \\
\hline Mature love & & & Sense of belonging \\
\hline \multirow[t]{2}{*}{ Meaning in life } & & & Reciprocation of favors \\
\hline & & & Healthy \\
\hline
\end{tabular}

Source: Schwartz (1994)

*Indicates items selected for the abbreviated scale. 
Searching more directly for a link between values and environmental attitudes, Stern et al. (1995) reached a different conclusion. These researchers con- ducted telephone interviews with randomly selected adults in Virginia. The three environmental attitudes (i.e. egoistic, socialaltruistic, and biospheric) were measured as beliefs about the consequences of environmental conditions for the individual (two items), all people (two items), or plants and animals (four items). To examine the link between values and attitudes, Stern et al.(1995) selected items from the selftranscendence dimension of Schwartz's (1992) instrument to reflect biospherism and socialaltruism, and items from self-enhancement to reflect egoism. The survey also contained valueitems from tradition and open- ness to change. Results indicated that 'the biospheric value orientation that appears in theliterature on environmentalism cannot yet be differentiated from a more generalized self-transcendent value cluster in the general population'. (Stern et al., 1995, p. 1630). This conclusion was supported by a factor analysis of Schwartz's value-items, in which the factor loadings failed to reveal a distinct biospheric factor, and instead supported a general factor in which biospheric and social-altruistic items loaded together. However, these findings are not surprising given that both the biospheric and social-altruistic values were chosen from the same factor of Schwartz's model- self-transcendence. When the self-transcendence (biospherismaltruism) factor and self-enhancement (egoism) factor, along with Schwartz's openness and tradition factors were regressed onto each of the three separate measures of environmental attitudes, results indicated that self-transcendence correlated positively on all three measures. Self-enhancement correlated negatively with biospherism, and tradition correlated negatively with biospherism and egoism. These results fail to provide support for the tripartite classification of different value-based environmental attitudes. See also Karp (1996).

One problem that arises from this research is how to measure environmental attitudes. The NEP represents one widely used approach, but it is limited in that it measures general environmental concern. As suggested above, environmental attitudes can be viewed as resulting from a person's system of values, and it should be possible to distinguish different clusters of attitudes organized around different values (Schultz \& Oskamp, 1997). Stern et al. (1995) used Schwartz's valueitems (along with a few specially created items) on the untested assumption that the selected values determined the attitudes. A recently published scale by Thompson and Barton (1994) pro- vides a third alternative measure of environmental attitudes. Their scale is designed to measure two (rather than three) value-based environmental attitude clusters. Both sets of attitudes reflect concern for environ- mental issues, but for different underlying reasons. Ecocentric concern centers on the instrinsic value of plants and animals. In contrast, anthropocentric concern is based on the effect that environmental damage will have on the quality of life for all humans. Thus, Thompson and Barton (1994) have collapsed social-altruistic and egoistic into one underlying value which emphasizes humans - both the self and others. Be- sides the original two studies by Thompson and Bar- ton (1994), no published research has used this scale.

The evidence reviewed above provides only limited support for a distinct set of environmental attitudes, and even less evidence for a link between these attitudes and a person's values. The present study was de- signed to examine the link between environmental attitudes and values in the U.S., and also in several Spanish speaking countries. We aim to show that values influence environmental attitudes. Specifically, we predicted that self-transcendent values (i.e. benevolence and universalism) would be positively related to ecocentrism, negatively related to anthropocentrism, and positively related to the New Environmental Paradigm. We expected to find these relationships across countries. In addition, we predicted that traditional values (i.e. tradition, conformity, security) would be negatively related to the NEP scale. This pre- diction was based on Dunlap's (Dunlap \& Van Liere, 1978; Dunlap et al., 1992) conceptualization of the NEP as a cluster of attitudes that are emerging from the dominant social paradigm (at least in the U.S.), and should therefore be negatively related to values of conformity, security, and tradition. 


\section{Cross-cultural research on environmental concern}

To date, there have been very few cross-cultural studies of environmental attitudes or behaviors. We will briefly review the cross-cultural evidence currently available, giving special attention to studies con- ducted with Hispanic and Latino samples - the focus of this paper. ${ }^{1}$

Some authors have argued that environmental concern is a postmaterial value-a set of attitudes that develops among wealthy people once the more basic needs of food and safety have been met (Inglehart, 1990; Buttel, 1992). This line of reasoning leads to the prediction that developing nations, like many Latin American countries, should be less concerned about environmental issues than the United States or European countries. This predicted positive relationship between SES and environmental concern has been found in research with entirely U.S. participants (for a review see Schultz et al., 1995). However, when examined across countries, the evidence shows an entirely different relationship.

Studies comparing non Hispanic U.S. respondents with Hispanic respondents (either immigrants to the U.S., or multinational studies) consistently find the Hispanic to be more concerned about environmental issues (cf. Noe \& Snow, 1990; Schultz et al., in press). In the largest environmental survey conducted to date, Dunlap et al. (1993) examined environmental attitudes in 24 countries (see also Dunlap \& Mertig, 1995). The sample included both industrialized (e.g. Canada, United States, Japan, Germany, Great Britain, and Denmark) and developing nations (e.g. Mexico, India, Chile, Turkey, South Korea, and Brazil). When asked the question 'What do you think is the most important problem facing our nation today?', environmental concern was listed by $11 \%$ of U.S. respondents, and $29 \%$ of Mexican respondents. Mexican, and other Latino respondents, consistently answered the poll questions in a more pro-environmental manner. When Dunlap and Mertig (1995) correlated nation-level GNP per ca- pita with measures of support for environmental protection among the 24 countries in their sample, they found a strong negative correlation $(r=-079)$. Clearly the traditional wisdom that environmental concern is a luxury afforded by only the wealthy is un- founded cross-culturally.

An alternative explanation for these findings, and one proposed by many authors, although seldom studied directly, is that culture plays an important role in determining environmental attitudes (Chavez, 1984; Lynch, 1993; Schultz et al., in press). We define culture as a set of attitudes, values, beliefs, and behaviors shared by a group of people, and communicated from one generation to the next (Barnouw, 1985). Lynch (1993) outlined several key differences between the Latino and Anglo views of the environment. First, Anglo environmentalism is characterized by a reliance on technical solutions, while Latino environ- mentalism focuses more on communal solutions. Secondly, Latin American environmentalism is characterized by a humans-in-nature view, while Anglos tend to view humans as protectors or consumers of nature. Both of these differences are core components of the environmental paradigm just beginning to emerge in the United States, and should be reflected in high scores on both the NEP scale, and Thompson and Barton's (1994) ecocentric scale. Thus, we predicted that Latin American countries would score higher on the NEP and the ecocentrism scale than U.S. respondents. In addition, we predicted that the value of tradition may not show the same negative relationship with NEP and ecocentrism that we predicted for U.S. respondents.

Taken together, this research suggests that a high percentage of people around the world are concerned about the quality of the environment, and that respondents from Latin American countries tend to be more concerned than U.S. respondents. However, in order to more fully understand environmental attitudes, it is necessary to go beyond environmental concern and examine the

1We use the term Latino to refer people from Latin America (i.e. Central or South America). In contrast, we use the term Hispanic to refer more broadly to people of Spanish descent. Thus, Hispanic is a broader term that encompasses the term Latino. 
underlying bases for these attitudes. Stern and Dietz (1994) have provided a useful theoretical framework for such an investigation, but there is little empirical evidence that values are related to environmental attitudes. The present study examines the relationship between environmental attitudes and values in 14 countries.

\section{Participants}

\section{Methodology}

Participants in the study were undergraduates at colleges and universities in Europe, Latin America, and the United States. For the purposes of statistical power, we attempted to obtain a minimum of 120 participants from each country. Respondents were college undergraduates enrolled in social or behavioral science courses at universities in Argentina, Canada, Colombia, Costa Rica, the Dominican Republic, El Salvador, Ecuador, Mexico, Panama, Peru, Paraguay, Spain, the United States, and Venezuela. The U.S. respondents were an ethnically diverse cross-section of college students. Spanish-speaking countries provide a diverse population along many dimensions and have been traditionally under-represented in the research literature (Sloan, 1990; Triandis, 1990). Demographic characteristics of the samples are shown in Table 2.

\section{Materials}

A four-page questionnaire was developed to measure environmental attitudes, values, self-reported pro-environmental behaviors, and demographics. Environ- mental attitudes were assessed with three scales. The first two were ecocentric and anthropocentric environmental attitudes, measured using items from Thompson and Barton's (1994) scale. 
TABLE 2

Demographic characteristics of sample from each country

\begin{tabular}{|l|l|l|l|l|}
\hline Country & $\begin{array}{l}\text { Gender (\% of } \\
\text { female) }\end{array}$ & Age & $\begin{array}{l}\text { Relative } \\
\text { SES* }\end{array}$ & $\begin{array}{l}\text { Strength of religious } \\
\text { beliefs }^{\text {t }}\end{array}$ \\
\hline Argentina & 59 & 24 & $4-96$ & $2-77$ \\
\hline Canada & 72 & 23 & $5-36$ & $3-23$ \\
\hline Colombia & 80 & 24 & $5-44$ & $3-57$ \\
\hline Costa Rica & 64 & 26 & $4-61$ & $3-71$ \\
\hline $\begin{array}{l}\text { Dominican } \\
\text { Republic }\end{array}$ & 56 & 21 & $5-75$ & $4-16$ \\
\hline El Salvador & 64 & 26 & $3-37$ & $4-26$ \\
\hline Ecuador & 53 & 28 & $6-31$ & $4-44$ \\
\hline Mexico & 37 & 37 & $5-07$ & $2-80$ \\
\hline Panama & 68 & 24 & $5-67$ & $4-18$ \\
\hline Peru & 70 & 24 & $5-13$ & $3-50$ \\
\hline Paraguay & 60 & 25 & $5-71$ & $3-86$ \\
\hline Spain & 64 & 23 & $5-01$ & $2-38$ \\
\hline United States & 71 & 21 & $5-62$ & $3-75$ \\
\hline Venezuela & 59 & 25 & $5-93$ & $3-74$ \\
\hline
\end{tabular}

*Question read: relative to the people in your country, would you say that your family is: response categories ranged from 1 (lower class) to 10 (upper class).

${ }^{\mathrm{t}}$ Question read: how important is religion in your life? Response categories ranged from 1 (not important) to 5 (very important).

Responses were made on a 5 point Likert scale ranging from strongly agree to strongly disagree. Seven items were selected to represent ecocentric (items 2, 5, 7, 26, 30, 32, 33) and anthropocentric attitudes (items 4, 11, 14, 22, 24, 27, 29). These items were selected because they loaded highly on a factor-analysis of pilot data from 75 U.S. college students, they were easy to translate into Spanish, and at face value represent the dimensions conceptualized by Thompson and Barton (1994).

The third measure was the revised version of the New Environmental Paradigm scale (Dunlap et al., 1992). The revised NEP scale contains 15 items which are rated on a 5 -point Likert scale. The scale is de- signed to measure the degree to which peopleview humans as part of nature, rather than consumers or protectors of nature.

Values were measured using items from Schwartz's values survey (Schwartz, 1992, 1994), shown in Table1. Because of space constraints, all 56 items were not used. Following Schultz and Zelezny (1998) we selected 37 items. Items were selected based on the emperical locations of each value in regions generated from a series of smallest space analyses reported by Schwartz (1994). We selected the four items with the greatest frequency of occurrence in each of the ten primary regions; the selected items were those that emerged most often in the appropriate value- type region in 97 independent samples from 44 countries. Each of the value-items was rated 'as a guiding principle in my life' from 0 not important to 7 (extreme importance). Values to which the respondent was opposed were scored -1 . The items used in the survey, the ten value-types, and the four higher-order constructs are presented in Table 1.

The survey was initially developed in English, pilot tested with 75 United States undergraduates, and translated into Spanish by two native speakers, one from Mexico and the other from 
Guatemala. The sur- vey was then back-translated from Spanish to English. The original and back-translated questions were compared, and modifications were made to the Spanish items to equate the two versions. Finally, the modified version was pilot tested with fluent Spanish speakers from Spain, Mexico, and Argentina.

\section{Design and procedure}

A network of contacts at universities in English and Spanish speaking countries throughout the world cooperated in distributing and returning the questionnaires. All of the contacts were university professors or administrators. Data from the United States were collected by the authors at their respective institutions. Each contact received a packet containing between 100 and 200 questionnaires, depending on the number of students with whom they interacted. The questionnaires were administered to groups of students who completed them in the classroom. Students responded voluntarily and were not compensated for their participation. Likewise, contacts were not compensated. The packet also contained a debriefing sheet and a postage-paid return envelope.

A total of 3400 questionnaires were mailed out, and 2160 were returned. Thereturned questionnaires were divided as follows: Argentina $(n=54)$, Canada $(n=96)$, Colombia $(n=149)$, Costa Rica $(n=213)$, the Domini- can Republic $(n=121)$, El Salvador $(n=194)$, Ecuador $(n=$ 201), Mexico $(n=65)$, Panama $(n=100)$, Peru $(n=224)$, Paraguay $(n=200)$, Spain $(n=104)$, the United States $(n=245)$, and Venezuela $(n=194)$.

\section{Results}

The purpose of this study was to measure environ- mental attitudes across a diverse set of English and Spanish-speaking countries, and to examine the relationship between these attitudes and values.

\section{Scale construction}

New environmental paradigm (revised). The original New Environmental Paradigm (Dunlap \& Van Liere, 1978) has been shown to have good internal reliability with U.S. samples. However, crosscultural research has demonstrated difficulty in translating several of the items (Noe \& Snow, 1990; Schultz \& Zelezny, 1998). Reliability coefficients for the 15 -item scale were calculated separately for each country. The alpha coefficients ranged from 081 in the U.S. to 047 in the Dominican Republic. An examination of the item-total correlations revealed one item that detracted from the scale in several countries. To ensure that scale scores were comparable, this item was excluded for all respondents. ${ }^{2}$ The modified scale showed improved internal consistency with a combined alpha reliability across countries of 0-70.

Ecocentrism-anthropocentrism. A similar procedure was used to assess the reliability of Thompson and Barton's (1994) ecocentrism and anthropocentr- ism scales. Alpha reliabilities were calculated sepa- rately for each country, and an item analysis was performed to identify inconsistent items. Results indicated that none of the items detracted from either scale. The alpha coefficients for ecocentrism ranged from 080 in El Salvador to 060 in Spain, with a combined average of 0 73. Alpha reliabilities for the anthropocentrism scale ranged from 081 in Mexico to 064 in the Dominican Republic, with a combined average of 0 74. Ecocentrism and anthropocentrism were significantly positively correlated in eight of the 14 samples: Dominican

2 The excluded item was 'The earth has plenty of natural resources if we just learn how to develop them'. (reverse coded). 
Republic ( $r=0$-28), Panama ( $r=0-28)$, Colombia ( $r=0-29)$, Peru $(r=0-24)$, El Salvador $(r=0-43)$, Venezuela ( $r=0-16)$, Ecuador $(r=0-30)$, and Paraguay $(r=0-43)$. The average correlation across the 14 samples was $r=0-25, p<0001)$.

Ecocentrism was positively related to NEP scores in all samples; the combined correlation coefficient was $r=0-44, p<0-001$. Similarly, anthropocentrism was significantly negatively related to NEP scores in several samples, with a combined effect of $r=-0-20, p<0-001$.

Values. Schwartz's value-items were divided into the ten value types listed in Table 1. Likert responses to each item were averaged to produce separate scores. Because Schwartz's values are considered to be universal across cultures, reliability coefficients were not calculated separately by country. Means and standard deviations for the ten value types are presented in Table 3.

\section{Comparisons across countries}

The three measures of environmental attitudes were compared across the 14 countries. Scores on the NEP scale, the seven-item anthropocentrism scale, and the seven-item ecocentrism scale are shown in Table 3. A one-way MANOVA comparing the 14 countries on the three dependent variables revealed a significant over- all effect $(F(39,6303)=13-03$; pillais $=0-24, p<0-001)$. Follow-up univariate tests revealed significant country-level differences on each dependent variable: $\operatorname{NEP}(F(13,2101)=1737, p<0$ 001). Mean scores and 95\% confidence intervals for the NEP scale are shown in Figure 1. As can be seen in the Figure, none of the samples scores were significantly lower than the U.S. sample, and ten of the samples were significantly higher (only the Dominican Republic, Ecuador, and Peru were not significantly higher).

\section{A value-basis for environmental attitudes}

The relationship between values and environmental attitudes was tested through a series of regression analyses, calculated separately for each country. For each regression analysis, the ten value types were entered as a block.

The overall results for the New Environmental Paradigm supported our predictions - NEP scale scores were predicted by tradition, power, and universalism. Although the linear model worked better in some samples than others, the general pattern of results was relatively consistent across samples (Argentina $R^{2}=0-17$; Canada $R^{2}=0-21$; Colombia $R^{2}=0-21$; Costa Rica $R^{2}$ $=0-11$; Dominican Republic $R^{2}=0-17$; El Salvador $R^{2}=0-06$; Ecuador $R^{2}=0-15$; Mexico $R^{2}=0-19$; Panama $R^{2}=0-08$; Peru $R^{2}=0-12$; Paraguay $R^{2}=0-07$; Spain $R^{2}=0-15$; United States $R^{2}=0-39$, and Venezuela $R^{2}=0-13$ ). Because of the consistency in the prediction model across samples, a combined regression analysis was performed. The results are shown in Table 4. As can be seen in the table, universalism was a strong positive predictor, power was a negative predictor, and tradition was a negative predictor.

A similar analytic procedure was followed in analyzing the ecocentrism and anthropocentrism scale scores. For ecocentrism, results were similar to those found for the NEP scale: universalism was a strong positive predictor, power was a negative predictor, and tradition was a negative predictor. The linear model worked exceptionally well in most of the samples: Argentina $R^{2}=0-34$; Canada $R^{2}=0-24$; Colombia $R^{2}=0-07$; Costa Rica $R^{2}=0-07$; Dominican Republic $R^{2}=0-21$; El

Salvador $R^{2}=0-18$; Ecuador $R^{2}=0-16$; Mexico $R^{2}=0-15$; Panama $R^{2}=0-14$; Peru $R^{2}=0-10$; Paraguay $R^{2}=0-17$; Spain $R^{2}=0-20$; United States $R^{2}=0-37$, and Venezuela $R^{2}=0-17$. The combined results are shown in Table 4. Overall, the ten variables were able to explain $12 \%$ of the total variance. 
TABLE 3

Means and standard deviations for values by country

\begin{tabular}{|c|c|c|c|c|c|c|c|c|c|c|c|c|c|c|}
\hline \multirow[b]{2}{*}{ Scale } & \multicolumn{2}{|c|}{ Argentina } & \multicolumn{2}{|c|}{ Canada } & \multicolumn{2}{|c|}{ Colombia } & \multicolumn{2}{|c|}{ Costa Rica } & \multicolumn{2}{|c|}{$\begin{array}{l}\text { Dominican } \\
\text { Republic }\end{array}$} & \multicolumn{2}{|c|}{ El Salvador } & \multicolumn{2}{|c|}{ Ecuador } \\
\hline & Mean & S.D & Mean & S.D & Mean & S.D & Mean & S.D & Mean & S.D & Mean & S.D & Mean & S.D \\
\hline \multicolumn{15}{|l|}{ Environmental } \\
\hline NEP & $3-83$ & $0-41$ & $4-11$ & $0-40$ & $4-01$ & $0-40$ & $4-08$ & $0-45$ & $3-75$ & $0-37$ & $3-93$ & $0-43$ & $3-69$ & $0-45$ \\
\hline Ecocentrism & $4-13$ & $0-50$ & $4-33$ & $0-43$ & $4-36$ & $0-54$ & $4-34$ & $0-51$ & $4-26$ & $0-47$ & $4-35$ & $0-64$ & $4-24$ & $0-50$ \\
\hline Anthropocentric & $3-18$ & $0-58$ & $3-08$ & $0-60$ & $3-51$ & $0-66$ & $3-37$ & $0-77$ & $3-70$ & $0-58$ & $3-74$ & $0-70$ & $3-85$ & $0-59$ \\
\hline \multicolumn{15}{|l|}{ Values } \\
\hline Power & $3-09$ & $1-70$ & $3-59$ & $1-62$ & $4-06$ & $1-54$ & $3-28$ & $1-98$ & $4-35$ & $1-99$ & $3-17$ & $2-25$ & $5-10$ & $1-70$ \\
\hline Achievement & $5-53$ & $1-14$ & $5-72$ & $1-00$ & $5-76$ & $1-25$ & $5-47$ & $1-27$ & $5-90$ & $1-27$ & $5-63$ & $1-52$ & $6-16$ & $0-99$ \\
\hline Hedonism & $6-00$ & $1-67$ & $6-25$ & $1-32$ & $6-16$ & $1-41$ & $6-15$ & $1-48$ & $6-33$ & $1-44$ & $5-68$ & $2-34$ & $6-07$ & $1-46$ \\
\hline Stimulation & $5-24$ & $1-21$ & $5-00$ & $1-35$ & $5-62$ & $1-17$ & $5-36$ & $1-54$ & $5-76$ & $1-47$ & $5-33$ & $2-01$ & $5-95$ & $1-04$ \\
\hline Self-direction & $5-96$ & $0-87$ & $5-99$ & $0-95$ & $6-05$ & $0-99$ & $6-13$ & $0-88$ & $6-16$ & $0-97$ & $6-44$ & $0-89$ & $6-22$ & $0-75$ \\
\hline Universalism & $5-55$ & $1-01$ & $5-67$ & $1-13$ & $6-03$ & $0-93$ & $6-13$ & $0-98$ & $5-91$ & $0-98$ & $6-38$ & $0-93$ & $6-08$ & $0-90$ \\
\hline Benevolence & $5-76$ & $1-11$ & $6-34$ & $0-88$ & $6-15$ & $0-85$ & $6-20$ & $1-05$ & $6-33$ & $1-00$ & $6-45$ & $0-97$ & $6-40$ & $0-73$ \\
\hline Tradition & $4-24$ & $1-62$ & $4-57$ & $1-23$ & $4-72$ & $1-51$ & $5-25$ & $1-47$ & $5-71$ & $1-19$ & $5-87$ & $1-39$ & $5-86$ & $1-06$ \\
\hline Conformity & $4-97$ & $1-21$ & $5-31$ & $0-94$ & $5-63$ & $1-24$ & $5-62$ & $1-31$ & $6-13$ & $1-00$ & $6-31$ & $1-06$ & $6-27$ & $0-82$ \\
\hline Security & $5-32$ & $1-23$ & $5-58$ & $0-99$ & $5-90$ & $1-09$ & $5-77$ & $1-29$ & $6-30$ & $2-73$ & $6-34$ & $0-98$ & $6-22$ & $0-86$ \\
\hline
\end{tabular}

\begin{tabular}{|c|c|c|c|c|c|c|c|c|c|c|c|c|c|c|}
\hline & \multicolumn{2}{|c|}{ Mexico } & \multicolumn{2}{|c|}{ Panama } & \multicolumn{2}{|l|}{ Peru } & \multicolumn{2}{|c|}{ Paraguay } & \multicolumn{2}{|l|}{ Spain } & \multicolumn{2}{|c|}{ United States } & \multicolumn{2}{|c|}{ Venezuela } \\
\hline Scale & Mean & S.D & Mean & S.D & Mean & S.D & Mean & S.D & Mean & S.D & Mean & S.D & Mean & S.D \\
\hline Environmental & & & & & & & & & & & & & & \\
\hline NEP & $3-88$ & $0-40$ & $3-94$ & $0-36$ & $3-75$ & $0-38$ & $3-89$ & $0-41$ & $3-83$ & $0-45$ & $3-67$ & $0-53$ & $3-91$ & $0-39$ \\
\hline Ecocentrism & $4-07$ & $0-60$ & $4-44$ & $0-43$ & $4-21$ & $0-46$ & $4-36$ & $0-51$ & $4-08$ & $0-43$ & $4-09$ & $0-52$ & $4-36$ & $0-46$ \\
\hline Anthropocentric & 3-39 & $0-78$ & 3-75 & $0-66$ & $3-59$ & $0-61$ & $3-64$ & $0-65$ & $2-98$ & $0-68$ & $3-26$ & $0-60$ & $3-54$ & $0-63$ \\
\hline Values & & & & & & & & & & & & & & \\
\hline Power & $3-54$ & $2-01$ & $4-96$ & $1-40$ & $4-20$ & $1-66$ & $3-53$ & $1-76$ & $2-90$ & $1-89$ & $4-21$ & $1-62$ & $4-20$ & $1-64$ \\
\hline Achievement & $5-56$ & $1-41$ & $6-38$ & $0-73$ & $5-67$ & $1-11$ & $5-43$ & $1-35$ & $4-93$ & $1-69$ & $5-88$ & $1-10$ & $5-97$ & 1-03 \\
\hline Hedonism & $5-76$ & $1-59$ & 6-41 & $1-01$ & $5-77$ & $4-46$ & $5-87$ & $1-66$ & 6-39 & $1-02$ & 6-09 & $1-46$ & 6-41 & 1-08 \\
\hline Stimulation & $5-27$ & $1-52$ & 5-91 & $0-96$ & $5-34$ & $1-20$ & 5-34 & $1-14$ & $5-13$ & $1-29$ & $4-86$ & $1-41$ & $5-66$ & $1-03$ \\
\hline Self-direction & $6-13$ & $1-12$ & $6-37$ & $0-60$ & $5-94$ & $0-93$ & $6-10$ & $0-85$ & $6-01$ & $0-76$ & $5-92$ & $0-95$ & $6-26$ & $0-72$ \\
\hline Universalism & 6-02 & $0-87$ & 6-24 & $0-82$ & $5-58$ & $1-10$ & 6-09 & $0-89$ & $5-80$ & $0-99$ & 5-31 & $1-19$ & 6-01 & $0-90$ \\
\hline Benevolence & $5-62$ & $1-22$ & $6-42$ & $0-76$ & 5-91 & $0-93$ & 6-19 & $0-88$ & $5-76$ & $1-04$ & 6-19 & $0-95$ & 6-28 & $0-73$ \\
\hline Tradition & $4-67$ & $1-64$ & 5-89 & $0-86$ & $4-46$ & $1-39$ & $5-32$ & $1-22$ & $4-24$ & $1-65$ & $4-82$ & $1-37$ & 5-14 & $1-31$ \\
\hline Conformity & $5-34$ & $1-51$ & 6-19 & $0-74$ & $5-27$ & $1-17$ & 5-69 & $1-16$ & $4-71$ & $1-59$ & 5-39 & $1-18$ & $5-80$ & 1-02 \\
\hline Security & 5-69 & $1-27$ & 6-23 & $0-74$ & $5-52$ & $1-16$ & $5-67$ & $1-08$ & $5-29$ & $1-46$ & $5-48$ & $1-21$ & $6-07$ & $0-83$ \\
\hline
\end{tabular}

Values as Predictors of Environmental Attitudes 


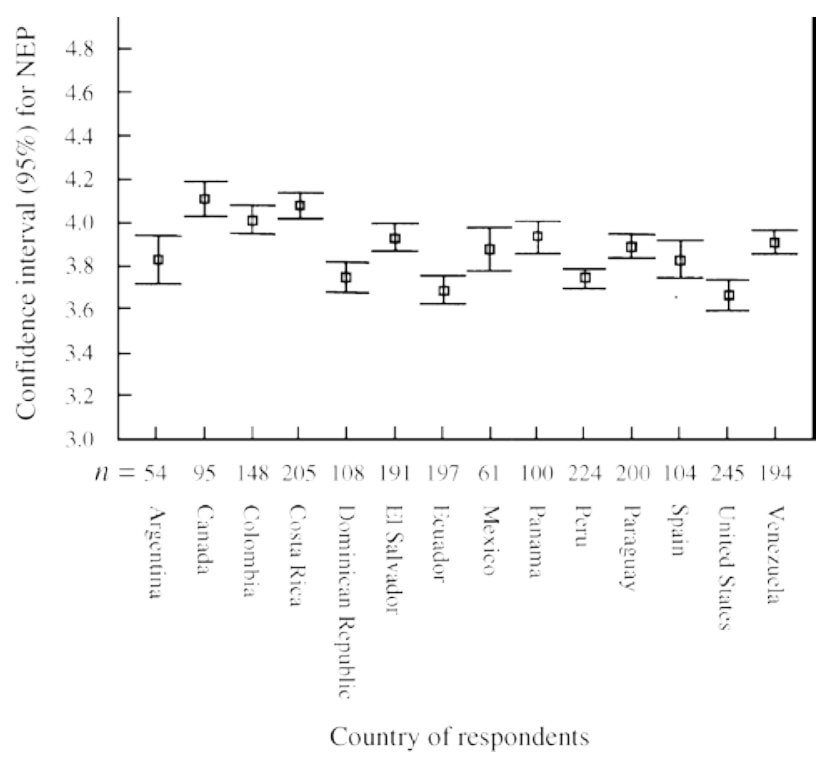

FIGURE 1. New Environmental Paradigm scores across countries.

The results from anthropocentrism suggest a very different underlying value basis than that observed for the NEP or ecocentrism scale. Three consistent findings emerged from the countryby-country analyses. First, unlike the prior two measures, universal- ism was not predictive of anthropocentric concerns, and in fact, benevolence (the value type which together with universalism comprises self-transcendence) was negatively related to anthropocentrism. The second consistent finding was that power was positively predictive of anthropocentric concerns. Final- ly, tradition, conformity, and security - the three value-types whichmakeupthetradition higher-order value-each made unique positive contributions to the prediction of anthropocentric concerns. The combined results from the total sample is shown in Table 4. Overall, the ten value types explained $15 \%$ of the variance. The separate analyses showed a good fit of the linear model across samples (Argentina $R^{2}=0-22$; Canada $R^{2}=0-16$; Colombia $R^{2}=0-14$; Costa Rica $R^{2}=0$ 17; Dominican Republic $R^{2}=0-09$; El Salvador $R^{2}=0-22$; Ecuador $R^{2}=0-11$; Mexico $R^{2}=0$ 41; Panama $R^{2}=0-27$; Peru $R^{2}=0-14$; Paraguay $R^{2}=0-07$; Spain $R^{2}=0$-30; United States $R^{2}=$ $0-33$, and Venezuela $R^{2}=0-15$.

\section{Discussion}

The results from our multinational study provide support for the value-basis theory; we found the predicted relationships between environmental attitudes and values. In addition, we found U.S. respondents scored lower on the New Environmental Paradigm than respondents from all countries except the Dominican Republic, Ecuador, and Peru. These results are consistent with recent findings by Dunlap et al. (1994). The findings are contrary to the notion that environmental concern is a postmaterial attitude, and suggest that other factors must be considered in understanding environmental concern. 
TABLE 4

Results from regression analyses using values to predict environmental attitudes

\begin{tabular}{|c|c|c|c|c|c|c|c|c|c|}
\hline \multirow[b]{2}{*}{ Value type } & \multicolumn{3}{|c|}{$\begin{array}{l}\text { New Environmental } \\
\text { Paradigm }\end{array}$} & \multicolumn{3}{|l|}{ Ecocentrism } & \multicolumn{3}{|c|}{ Anthropocentrism } \\
\hline & B & Beta & $t$ & B & Beta & $t$ & B & Beta & $t$ \\
\hline Universalism & $0-11$ & $0-25$ & $8-77 * * *$ & $0-16$ & $0-31$ & $11-11^{* * *}$ & $-0-01$ & $-0-01$ & $-0-44$ \\
\hline Benevolence & $0-02$ & $0-03$ & $1-11$ & $0-02$ & $0-03$ & $1-17$ & $-0-04$ & $-0-06$ & $\begin{array}{l}-2- \\
13^{*}\end{array}$ \\
\hline Power & $-0-05$ & $-0-22$ & $-7-52 * * *$ & $-0-03$ & $-0-10$ & $-3-40 * * *$ & $0-06$ & $0-15$ & $5-36 * * *$ \\
\hline Achievement & $0-01$ & $0-04$ & $1-25$ & $-0-01$ & $-0-02$ & $-0-54$ & $-0-00$ & $-0-00$ & $-0-16$ \\
\hline $\begin{array}{l}\text { Self- } \\
\text { direction } \\
\end{array}$ & $0-00$ & $0-00$ & $0-14$ & $0-00$ & $0-00$ & $0-19$ & $0-02$ & $0-02$ & $0-90$ \\
\hline Stimulation & $0-00$ & $0-01$ & $0-25$ & $0-01$ & $0-03$ & $1-04$ & $0-02$ & $0-04$ & $1-58$ \\
\hline Hedonism & $0-01$ & $0-04$ & $1-48$ & $0-01$ & $0-02$ & $0-79$ & $-0-01$ & $-0-03$ & $-1-18$ \\
\hline Tradition & $-0-04$ & $-0-14$ & $-3-88^{* * *}$ & $-0-03$ & $-0-08$ & $-2-00^{*}$ & $0-08$ & $0-16$ & $4-53 * * *$ \\
\hline Conformity & $0-03$ & 0-09 & $2-25 *$ & $0-04$ & 0-09 & $2-21 *$ & $0-05$ & $0-08$ & $2-05 *$ \\
\hline Security & $-0-01$ & $-0-02$ & $-0-72$ & $-0-01$ & $-0-02$ & $-0-65$ & $0-06$ & $0-12$ & $4-12 * * *$ \\
\hline Constant & $3-25$ & & & & & & & & \\
\hline \multirow{2}{*}{$\begin{array}{l}\text { Final } \\
\text { statistics }\end{array}$} & $R^{2}=0-11$ & & & $R^{2}=0-12$ & & & $R^{2}=0-15$ & & \\
\hline & $\begin{array}{l}F(10,1912) \\
=22-48^{* * *}\end{array}$ & & & $\begin{array}{l}F(10,1912)= \\
25-99 * * *\end{array}$ & & & $\begin{array}{l}F(10,1912) \\
=33-92 * * *\end{array}$ & & \\
\hline
\end{tabular}

$* \mathrm{p}<0-05, * * * \mathrm{p}<0-001$

The findings from our regression analyses of Schwartz's universal values and measures of environmental attitudes found a clear pattern of effects. As predicted from Stern and Dietz's (1994) value-basis theory, self-transcendent values, particularly universalism, appear to be the primary values associated with NEP (positive) and ecocentrism (positive). This pattern was consistent across countries. We had predicted that tradition would be negatively related to NEP and ecocentrism in the U.S., but be- cause of cultural differences, we expected tradition to be positively predictive in Latin American samples. Our findings suggest that the new paradigm in which humans are viewed as an integral part of nature is emerging in Latin American countries just as it is in the U.S., and that Latin American environmental attitudes are similar in their underlying structure to those found among U.S. respondents.

An unexpected finding was that the self-enhancement value of power was negatively related to NEP and ecocentrism, and positively related to anthropocentrism. According to Stern and Dietz (1994), environmental attitudes are based on different underlying values which can be classified as egoistic, social-altruistic, or biospheric. The measures we adopted for this study, and the only published measures available to date, assess only biospheric and anthropocentric attitudes. The anthropocentric attitude cluster is organized around concern for humans (whether for the self or others) and is therefore both egoistic and anthropocentric. As discussed above, traditional values were predictive of anthropocentric concerns - a finding which reflects the social-altruistic component. However, the fact that power ( a self-enhancement value) was positively predictive of anthropocentric concerns, suggests an egoistic component as well. Further work with measurement should be able to distinguish three factors and differentiate between egoistic and social-altruistic concerns.

A remaining question is why self-transcendence values predict biospheric environmental attitudes (like ecocentrism and the NEP), while self-enhancement values like power predict egoistic attitudes (positively) and biospheric attitudes (negatively). The value-basis theory suggests that different attitudes are based on concerns about the harmful consequences that may result for different valued objects. That is, an egoist is concerned about environmental issues be- cause of the negative consequences that may result to self. The social-altruistic concerns are based on negative 
consequences to other people, and biospheric concerns for all living things. Stern et al. (1995) have further argued that these attitudes can be incorporated in a norm-activation model of helping (Schwartz, 1968, 1977), whereby each value must be activated to produce behaviour. From this perspective, pro-environmental attitudes and behaviors can be viewed as examples of helping. However, unlike thetypical paradigm in research on helping behaviour, the victim is abstract and the effects of the behaviour are not readily apparent. Nevertheless, viewing pro-environmental attitudes and behaviours as examples of helping suggests the applicability of a large body of theoretical work on altruism, egoism, and pro-social behavior.

We propose a slightly different interpretation. Self- transcendence is a measure of the degree to which a person values goals and ideals that are not directly linked to their notion of self (e.g. broad-minded, a world of beauty, loyal, honest, forgiving) while self-enhancement is the degree to which a person values goals and ideals that are directly linked with tangible rewards for self (e.g. successful, ambitious, wealth, social power).We propose that self-enhancement reflects a general orientation to self-benefit because people who score high on self-enhancement have a narrow definition of self that does not include other people or other living things. In contrast, selftranscendence reflects a broader cognitive representation of self, and measures the degree to which a person includes other people and other living things in their notion of self. It follows that values of self-transcendence would be positively associated with biospheric concerns, while values of selfenhancement would be positively related to less biospheric concerns and more egoistic concerns. We are suggesting that the New Environmental Paradigm, and more broadly biospheric environmental concerns, reflect the degree to which people define self as part of nature.

Although these results support the notion that values are linked with specific attitudes, several limitations need to be recognized. At a conceptual level, as is the case with other studies of environmental concern, the measurement of attitudes toward the environment is problematic. The New Environmental Paradigm has 20 years of research behind it, but it measures only one type of environmental attitude. Thompson and Barton's (1994) scale provides a useful starting point for a more refined measure, but it is limited in several ways. First, the anthropocentrism scale fails to distinguish between attitudes based on concern for self, and attitudes based on concern for others. Although linked by the common theme of concern for human life, the distinction between self and other is an important one to make in studying environmental attitudes.

Secondly, in the only two validation studies on the anthropocentrism-ecocentrism scales, reported by Thompson and Barton (1994), anthropocentrism correlated negatively with self reported behavior. One criterion for the validity of a measure of environmental attitudes should be its ability to predict behavior, and attitudes of concern should be linked with more proenvironmental behavior (or at least intentions) in some contexts. For instance, a person with egoistic concerns should engage in pro-environmental behaviors when it leads to personal rewards (e.g. recycling for money). Likewise, a person with social-altruistic concerns should engage in pro-environmental behavior when it is perceived as helping other people with- out direct personal benefits (e.g. volunteering to clean up after an oil spill).

Other limitations with this study are methodological. First, the sample on which these results are based is not representative. Participants in the study were college students - perhaps an elite sample that may not reflect the generally held views of others in their country. However, even though the sample was not re- presentative, it was comparable across countries. Be- cause all of the respondents in the study were college students, the country-level comparisons are based on similar people. A second methodological limitation is the possible confound of linguistic differences. The survey was initially developed in English, translated into Spanish, and back translated by two fluent Spanish speakers; we did not generate separate versions of the survey for each country. However, based on our pilot data and the fact that we used translators from different countries, we believe that the survey was generic enough to be understood equally well in all the countries sampled. 
Environmental problems are worldwide, and solutions to these problems must be made at a global level. However, very little multinational environmental re- search is being conducted. The study reported in this paper represents an initial attempt to understand values as a cultural variable involved in environmental concern. We believe that a multinational understanding of the values and motives that underlie environ- mental concern and behavior is needed before we can move toward more effective environmental policies and social interventions designed to increase proenvironmental behavior. In this paper, we have presented the results from a study of the relationship between environmental attitudes and values. In addition, we have suggested that recent theoretical re- search on helping behavior may provide a useful foundation from which to approach the study of environmental attitudes and behaviors.

\section{Acknowledgments}

Funding for this research was provided by a grant from the Society for the Psychological Study of Social Issues. For their invaluable assistance, we thank Sergio Aguilar, David Barkin, Roberto Bravo, Jim Wal- teres Colmenares, Melva Palacios de Mon, Anna Sartorio de Ponte, Judith Deshotels, Marcelina Alon- so de Tapia, Lissette Fernandez, Jose Anicama Gomez, Doris Hager, Jose Luis Henriquez, Luis Iberico, Car- los Luis Lafuente, Adriene Lazaroff, Daniel Mata- moros, Doug McKenzie-Mohr, Ricardo M. Morales, Leticia Ramos-Garza, Orialia Esther Romande Rivas, Edgar Salgado, Sara Beatriz Molina Yela, Edwin Ul- loa.We thank Kate Patterson, Rita Goldberg, Barbara Martinez, Margarita Cruz, and Kelly Bordeleau for their help with translation. We would also like to thank Sara Austin, Nancy Dalrymple, Sam King, and Chris Strong for their assistance in developing the survey and data entry, and Barbara Martinez and John Thomas for their assistance in data management.

Portions of this paper were presented at the meeting of the Society for the psychological Study of Social Issues, June, 1996, Ann Arbor, Michigan. 


\section{References}

Barnouw,V. (1985). Culture and personality. Chicago: Dorsey. Buttel, F. H. (1992).

Environmentalization: Origins, pro- cesses, and implications for rural social change. Rural Sociology 57, 1-27.

Chavez, J. (1984). The lost land: The Chicano image of the southwest. Albuquerque, NM: University of New Mexico Press.

Darley, J. \& Gilbert, D. (1985). Social psychological aspects of environmental psychology. In G. Lindzey \& E. Aronson (Eds), The Handbook of Social Psychology, Vol.2. New York: Random House, pp. 949-992.

Dunlap, R. \& Mertig, A. (1995). Global concern for the envir- onment: is affluence a prerequisite? Journal of Social Issues 51, 121-138.

Dunlap, R. E. \& Van Liere, K. (1978). The new environ- mental paradigm. Journal of Environmental Education 9, 10-19.

Dunlap, R., Van Liere, K., Mertig, A. \& Howell, R. (1992, August). Measuring endorsement of an ecological world- view: a revised NEP scale. Paper presented in the An- nual Meeting of the Rural Sociology Society, PA.

Dunlap, R., Gallup, G. \& Gallup, A. (1993). Of global concern: results of a health of the planet survey. Environment 35, 7-39.

Inglehart, R. (1990). Culture Shift in Advanced Industrial Society. Princeton, NJ: Princeton University Press.

Karp, D. G. (1996). Values and their effect on pro-environmental behaviour. Environmental and Behaviour 28, 111-133.

Kempton, W., Boster, J. \& Hartley, J. (1995). Environmental Values in American Culture. Cambridge, MA: MIT Press.

Lynch, B. D. (1993). The garden and the sea: U.S. Latino environmental discourses and mainstream environmentalism. Social Problems 40, 108-124.

Merchant, C. (1992). Radical Ecology. New York: Routledge.

Noe, F. P. \& Snow, R. (1990). Hispanic cultural influence on environmental concern. Journal of Environmental Education 21, 27-34.

Olson, J. \& Zanna, M. (1993). Attitudes and attitude change. Annual Review of Psychology 44, 117-154.

Rokeach, M. (1973). The Nature of Human Values. New York: Free Press.

Schultz, P. W. \& Oskamp, S. (1997, October). The motivational bases for environmental concern. Paper presented at the Society of Experimental Social Psychology, Toronto, Canada.

Schultz, P. W. \& Zelezny, L. (1998). Values and proenvironmental behaviour: a five country survey. Journal of Cross-Cultural Psychology 29, 540-558.

Schultz, P. W., Oskamp, S. \& Mainieri,T. (1995). Who recycles and when: a review of personal and situational factors. Journal of Environmental Psychology 15, 105-121.

Schultz, P. W., Unipan, J. B., \& Gamba, R. J. (in press). Acculturation and ecological worldview among Latino- Americans. Journal of Environmental Education.

Schwartz, S. H. (1968). Words, deeds, and the perception of consequences and responsibility in action situations. Journal of Personality and Social Psychology 10, 232-242. Schwartz, S. H. (1977). Normative influences on altruism. In L. Berkowitz (Ed.), Advances in Experimental Social Psychology, Vol.10. New York: Academic Press, pp. 221- 279.

Schwartz, S. H. (1992). Universals in the content and structure of values: Theoretical advances and empirical tests in 20 countries. In M. Zanna (Ed.), Advances in Experimental Social Psychology, Vol.25. Orlando, FL: Academic Press, pp. 1-65.

Schwartz, S. H. (1994). Are there universal aspects in the structure and contents of human values? Journal of Social Issues 50, 19-45.

Sloan, T. (1990). Psychology for the third world. Journal of Social Issues 46, 1-20.

Stern, P. \& Dietz, T. (1994). The value basis of environmental concern. Journal of Social Issues 56, 121-145. 
Stern, P., Dietz, T., Kalof, L. \& Guagnano, G. (1995). Values, beliefs, and proenvironmental action: attitude formation toward emergent attitude objects. Journal of Applied Social Psychology 25, 1611-1636.

Thompson, S. \& Barton, M. (1994). Ecocentric and anthropocentric attitudes toward the environment. Journal of Environmental Psychology 14, 149-157.

Triandis, H. (1990). Toward cross-cultural studies of individualism and collectivism in Latin America. Interamerican Journal of Psychology 24, 199-210. 